\title{
Media Industries and Engagement: A Dialogue across Industry and Academia
}

\author{
Annette Hill, Jeanette Steemers, Jane Roscoe, \\ Julie Donovan, and Douglas Wood'
}

Lund University, King's College London, London Film School, Formats Consultant, and Endemol Shine

\begin{abstract}
:
This article focuses on media engagement within the industry. The article takes the form of a dialogue between industry and academic researchers involved in a collaborative project on production and audience research on engagement (funded by the Wallenberg Foundation and in collaboration with Endemol Shine Group). Speakers from the film and television industry, and academic researchers working on media engagement, discuss how engagement is multifaceted, working across political and public spheres, policy and industry sectors, audiences and popular culture.
\end{abstract}

Keywords: Television Industries, Media Engagement, Cultural Value

This roundtable discussion took place at the Media Engagement symposium on May 3, 2016, at the University of Westminster. The discussion was chaired by Professor Jeanette Steemers, and included Julie Donovan, a formats consultant working on an industryacademic project with Lund University and Endemol Shine; Professor Annette Hill, Lund University, Sweden; Dr. Jane Roscoe, Director and CEO of the London Film School, and former head of acquisitions at SBS, Australia; and Douglas Wood, Director of Research and Insight, Endemol Shine Group.

\section{Introduction}

The focus of our dialogue is to learn how industry and academia think about and conceptualize engagement. The inspiration for this dialogue arises from a project Media Experiences (2013-16), funded by the Wallenberg Foundation (see http://mediaexperiences.blogg. lu.se/). The project conducted production and audience research on a range of television content. In this project, we asked a simple question: "How do creative producers craft content for audiences and how do audiences actually engage with this content?" We used qualitative, flexible research to explore this question across production practices and cultures of viewing. The research analyzed drama and entertainment formats, including The Bridge (Filmlance International), Utopia (Kudos), MasterChef (Endemol Shine), and Got to Dance (Princess), and the findings allowed us to unpack the idea of engagement and how different meanings of this idea can be of value across academic and industry research. 


\section{Jeanette Steemers: What is the value of research that bridges the gap between industry and academia?}

Douglas Wood: What attracted me to the project is the challenge of measurement for linear television. As traditional linear television viewing declines, and audiences fragment, the value of measurement and audience engagement is crucial for us. This research allowed us the luxury of talking to both creatives and audiences. In the commercial world, you rarely have the opportunity to do this type of research; typically, in our research, you go in with a problem that needs to be answered - "why isn't this storyline working?" We would never analyze the creative process itself: it's alien to us. So, it was fortunate to have a third party come in and explore this process of talking to creatives and audiences. It was a unique opportunity to understand what we do internally and how that relates to our audiences, and to think about the future of those audiences and where they may be in five or ten years' time.

Julie Donovan: As a consultant, I learned how to bridge the gap between industry and academia. We talked a lot about relationship management. We all trusted each other and the evolving process of this kind of unique research. For example, in the industry, we concentrate on pragmatic questions such as "What do you want?" and "How can we get it to you?" whereas the conversation from the academic perspective was to listen more and ask less questions, "We are looking into this, and how do we find it?" There is a different language. If you are going to maintain relationships across academic and industry sectors, then you have to make sure the conversation is dynamic and fluid. Producers have to know why they are involved and how to make the research relevant to the industry. The speed with which you can deliver research back to your contacts is really important to ensure that engagement with the industry.

Annette Hill: $\quad$ My experience of this kind of collaborative research is that relationship management is central. We took a flexible approach to the research where each case was fit for purpose for the genre, production culture, and culture of viewing. At each step in the process, our relationships with the creatives, within the team, and with audiences were a constant presence. As such, I began to understand that engagement within the industry is about the meaning of the term as relationships; the collaborative experiences of creatives working together to produce a drama, for example; and our relationships with these writers, directors, or actors and extras. Then, I also slowly understood the tensions surrounding the relationships between the creatives and the executive producers and broadcasters, one based on trust, but where trust can be broken by decisions from on high about marketing, or scheduling. And, finally, this kind of engagement within the industry connects with audiences, fans, and consumers, as the relationships across production and reception contexts make or break the overall success or failure of a show.

Jane Roscoe: $\quad$ As a broadcaster, you think about engagement differently than as an academic. There are often different languages and value systems at play, such as pragmatism in the industry and creative explorations in academia, or economic and cultural values. This research is identifying some of the gaps and some of those shared moments where we can expand and explore engagement further. 


\section{Jeanette Steemers: What does engagement mean within the cultural industries?}

Jane Roscoe: $\quad$ As an academic, I was more interested in engagement as meaning and that contrasts with my role as a broadcaster where everything is outcome focused. So when you are thinking about engagement, it might be the relationship between the producers and creatives and how you engage them to make something for the broadcaster, whereas when you think about audiences, it might be related to ratings, reach, and share which are more anonymous forms of engagement. At the same time, you might be thinking about the impact of programs on communities and public debates, and engagement takes a different form there as the value of public impact. There might also be strategic decisions you take about advertising as well. So, engagement is there at every level and is perceived and talked about in slightly different ways. And if I reflect on my role as an educator, students who are practical filmmakers are thinking about who the audience is or how to engage at an emotional level. Engagement is so dependent on context and how we position ourselves within these different commercial, public, and educational environments.

Douglas Wood: We are moving away from a single currency of engagement. Historically, the TV world was very much driven and judged on audience ratings, and this was the principal currency to measure both viewer engagement and commercial value. However, the growth of new platforms and digital services, such as Netflix, has resulted in a lot of TV content now falling outside of the traditional ratings measurements systems, so we are in a situation where engagement may mean a very different set of criteria depending on how you judge success. For example, a linear broadcaster such as BBC One will be more interested in a live TV audience for its content, whereas a service like Netflix, which is looking at the longer tail, will take into account the cumulative audience over a longer period of time. Additionally, for a service like Netflix, they also have to ensure that they provide enough quality content to keep their customers paying a monthly subscription. Faced with this audience fragmentation, as producers, we are increasingly being asked for platform-defining content, something that is unique, something that will find a voice and have cultural impact.

To be able to sell engagement, you are selling more than just a TV show-you are selling cultural resonance and viewer engagement. This is an increasingly important currency. We can clearly see this with the current demand for highquality drama, which plays very well in an on-demand world where binge watching and catch-up viewing have become the new normal. Both traditional broadcasters and new platforms are responding to changes in viewer behavior, and this has a direct impact on the type of shows that we produce. For example, when BBC One decided not to renew the drama Ripper Street after its second season due to low ratings, Amazon stepped in and subsequently commissioned a further three seasons. The reason for this was clear, that although Ripper Street had only garnered a relatively small audience in its domestic market, at an international level, the show had a global fan base and Amazon saw the value in taking over an existing TV brand with a proven track record. 


\section{Jeanette Steemers: How do producers think about engagement?}

Julie Donovan: As a producer, you are always thinking about audiences. Is this entertaining, interesting, surprising, informative? Have I pitched the show or item correctly at the target audience? Is the tone in line with the broadcasters' brand or time slot? The difficulty has been in the relatively slow way the industry has reacted to different forms of measurement. Producers make a great show that everyone is talking about and then they receive the overnight ratings and they are judged on the numbers, which may not reflect the level of conversation around the show. As a producer you can be deflated when you know your show has cult status, sometimes outside of the country where it is broadcast, but the local audience figures don't add up. So there is often this hidden audience that isn't or can't be measured. Even when it comes to social media, it can sound really impressive that you are trending on Twitter but that can mean very little to producers if their ratings are poor.

Jane Roscoe: $\quad$ That used to happen at SBS in Australia; we would come in and say, "We are trending on Twitter, why are our ratings so low?" What we didn't understand was why were people engaging with social media but not live television? It is difficult to measure engagement as relevance and impact. For example, when we started showing the Danish dramas in 2005 on SBS, the loyalty figures were very high but the reach and share were relatively low. With the popularity of Nordic Noir, we started to see something different with audiences, where people were very dedicated, and we asked ourselves how do we nurture them? Now, that question is even more relevant when there are so many different ways for us to engage and that is the kind of conversation we are all interested in; we are all concerned about impact and relevance.

Engagement starts to become about individuals' relationship to brands. That form of engagement can be the channel or the program, and it is very much about emotional connections. We want to connect with the values of a channel, for example. SBS is a multicultural broadcaster committed to values that support social inclusion and diversity. Viewers want brands to reflect their personal values, or to put it another way, we look to brands that seem to represent the values we hold. So, engagement starts to factor in broader social and political issues. Brands remain relevant when they can speak to these more emotional, personal concerns. It's these deeper experiences that are hard to measure and hard to articulate. This is another reason why academic work on audiences is so important-this is where we have a chance to explore some of that and to see what that means in practice.

Douglas Wood: For us as producers, we are no longer primarily driven by the overnight ratings, but rather we take into account the broader transmission window. The overnight ratings can give us a useful indication of initial performance, but it's not uncommon now for a show to double its audience once you take into account the catch-up audience. Also, we are increasingly thinking about our audiences across a wider spectrum of platforms, so a show that attracts a particular demographic on linear TV may bring in a different one across on-demand and digital platforms. And for us, we have to pull together these 
different audience metrics to judge the overall performance and engagement. For example, we produce the Mr. Bean animated series which airs on smaller broadcasters such as CITV in the United Kingdom and Super RTL in Germany, and the average TV audience will typically be under one million viewers. But this is just one part of the audience story - if you look at the brand on social media, Mr. Bean has over sixty-five million likes on Facebook which is an amazing amount of people who are potential viewers for the show. As producers, we understand that our viewers are now consuming TV content in different ways and we have to follow this audience and create content that works across all platforms.

\section{Jeanette Steemers: How does distribution impact on global and local audiences and the ways they engage with different content?}

Douglas Wood: We used to think about mass audiences in a static way, and that has completely transformed. In the traditional TV distribution model, we looked at the audience on a territory-by-territory basis and sold content for this mass audience. However, with the growth of global platforms and new opportunities for viewers to access video content everywhere, not always legitimately, we have seen new models emerge. For example, for a big US drama series, such as Game of Thrones, many international broadcasters will now air the series at the same time as, or as near as possible to, the US broadcast window to avoid the inevitable social media spoilers, or allow fans the opportunity to find this content online elsewhere, whereas global platforms, such as Netflix, can give a niche show wider exposure by harnessing these disparate global communities and make them a commercially viable mass audience.

This also impacts on the types of shows that get made, and we have seen a huge creative resurgence in scripted content, with more challenging and diverse titles being produced and sold. For example, the research on cult conspiracy drama Utopia was fascinating because although it only had a relatively small, but dedicated, audience for Channel 4 in the United Kingdom, its global cultural impact and appeal was undeniable. This research really brought home the potential of these untapped audiences when we think about the best destination for our content. And this bringing together of previously disparate audiences has a direct impact on the creative offer and has brought in new talent, both on and off screen, to the TV production business.

Julie Donovan: Shows move across platforms with a greater degree of fluidity. Their audiences can then follow them, if they are able, sometimes without extra cost but not often. Amazon, for example, picked up the Top Gear team for its rebranded Grand Tour, hoping to collect Top Gear's global audience. While the traditional BBC show suffered with the departure of the three presenters, it remains to be seen how successful the new Amazon format will be and how many people will subscribe to Amazon Prime just for this show. On a personal note, I recently discovered the Outlander TV series and greedily consumed series one on Netflix, only to find that I needed to subscribe to Amazon Prime 
to watch series two. That was a frustrating experience as a fan of the show, as I needed to subscribe to multiple pay platforms to watch a single brand. To pull the audiences to the platform, the content has to be really engaging to push people into new subscriptions or payment methods, and at some point, the costs of viewing will be beyond the reach of many ordinary TV viewers. That will be a new challenge for program funding models.

Annette Hill: What was so interesting with Utopia was Channel 4 took a risk with this experimental drama, knowing it would appeal to niche audiences. They marketed the drama in such inventive ways, drawing in a cult audience that would come to that channel for unique drama like this. The broadcaster also knew that many of their viewers would watch the drama on catch-up, and they made the series available for free over a long period of time to allow for binge watching and catch-up. All of this would suggest the broadcaster understood the relevance and impact of this drama for niche audiences of cult drama in the United Kingdom. And yet the numbers did not add up. The drama was too cult for national audiences. In our research on Utopia, we found the drama had global appeal, with a long tail of really engaged audiences around the world. Utopia is popular in countries such as Chile or Russia. They are watching the drama illegally, an invisible audience, and yet we can say they are highly engaged, and from an industry perspective, the drama had very high cultural resonance. There is a paradox here, where the new currency of engagement includes cultural resonance and yet the measurement systems are out of step with this development.

Jane Roscoe: $\quad$ Some of the new platforms are keen to know what attracts people to content and different types of experiences. That is what is so difficult, to capture and understand new currencies of engagement as psychological and emotional meaning. The industry does want to know how to measure more accurately and really tap into this kind of qualitative experience. Every bit of intelligence helps them stay one step ahead. The problem is finding the right persons to ask the right questions. That is where academia can find a valuable place within industry research.

Jeanette Steemers: There is this tension between global engagement and local engagement. How do you find the balance?

Jane Roscoe: The things we look for in entertainment are similar, emotional engagement, authenticity, identification; we are looking for a connection, and this goes right back to the early days of popular culture. What complicates it now are the choices and how we represent emotions or authenticity. This gives an opportunity for more specialized audiences and communities to gather around specific storytelling. That is why factual formats work so well because they are global properties indigenized. We talk about a global mediascape, but it is also about engaging people on a deeper level and you need local content for that. Netflix have recognized the value of global and local engagement; most of their content is pretty universal, but they know that to build communities, they need more local content. 
Annette Hill: In our research on the UK cookery format MasterChef, we found local audiences loved home-grown versions of the series. So in Denmark, MasterChef follows the brand and the building blocks of the competitive cooking show, but what audiences valued most about this local variation of the brand was its focus on Danish food and national traits in cooking good food from scratch, using all the scraps. People talked a lot about how the show was relevant to them because it symbolized authentic food, Danish cooking, and a down-toearth approach to food in family life. This is a good example of a global brand with local cultural resonance.

Douglas Wood: We are part of a global media world, and audiences are increasingly sophisticated in how they consume content. Certainly in terms of drama series, we have seen that time and again a good story and compelling characters are universally appealing regardless of the origin. We saw this with the local version of The Bridge in Scandinavia that found a global audience both for the original production and as an adapted format. However, in terms of non-scripted content, viewers seem to want authentic experiences and honesty from their formats. For example, last year, The Great British Bake Off was the highest rated show in the United Kingdom. In itself, a competitive baking format is not an obvious contender for the top rated show of the year; however, through authentic casting and honest storytelling, the audience connected with what they saw, they were engaged with it, and most importantly, they cared. Successful global formats work because they combine a proven structure with local sensibilities.

Julie Donovan: The big global entertainment brands manage this global format-local content relationship really well. There's a strong central format that can be re-produced with localized content and therefore more cultural relevance, for example, the Got Talent brand, Idols, or The Voice. In entertainment, that strong core format that can be adapted is the key to global success.

Jeanette Steemers: In current debates on public service media, we see a play-off between economic and cultural values of engagement. How can the industry respond to this?

Douglas Wood: In an ideal world, these cultural and economic values would be aligned, but at the moment, engagement is primarily measured in a one-dimensional, short-term way through a single metric which is the audience rating. But the history of television is built on ground-breaking shows which although they may not have delivered a large audience at the time have pushed the creative envelope further and brought new voices or experiences to the TV screen. It's a TV cliché, but many long-running series that we now consider cultural institutions were not immediately successful when they first aired. Public service media provide such an important arena for program creators to experiment with new ideas, and both the broadcasters and production community have a responsibility to seek out new ways of telling these stories and reflecting their diverse audiences. The natural outcome of judging 
success by just the immediate audience size is that we end up with an everdecreasing circle of similar shows that just seek to emulate the status quo. As broadcasters become increasingly risk-adverse, it's not uncommon to see a dearth of derivative format ideas following one breakthrough success. As program makers, we certainly look at the fringes of the media world to see what might be coming next, and it's often by looking at these smaller niche audiences that we can spot future trends and viewing patterns. This might include looking at social media communities, YouTube channels, or what's working across younger-skewing networks.

Annette Hill: The play-off is a sign of the tensions around the very meaning of the term engagement within media industries. If we see engagement as a performance indicator for economic targets, then this is a very one-dimensional understanding of the term. The television industry has dominated the definition of engagement as economic targets, and it is time we changed the conversation to include the cultural value of engagement as well. Creative producers experience the tensions between these two kinds of targets all the time. There is the cultural value of their work, which they know and understand; it's a language of emotion and storytelling and aesthetics, and then there is the economic value placed by the industry on their work, which is communicated by ratings in a way that is often hard to understand.

The type of research we have done is precisely to make an intervention in the industry so that we open up the language of engagement to include cultural as well as economic targets. Engagement is more than capturing the attention of audiences, it is making a connection, and in some cases, making a real difference to people's lives. We have studied drama where producers have wanted to make that connection with audiences and felt they failed because of low ratings. We were able to show producers that not only did they make a connection but their work had a lasting impact on audiences, in their daily lives, memories, and dreams. What is the value of dreams? This is what Douglas is talking about in terms of the new currencies of engagement.

Jane Roscoe: This is how we get the diversity debate wrong. The biggest issue at the moment is about diversity but what we keep doing is making a cultural argument for it around social cohesion, for example. The problem is we are not making an economic argument for diversity. And it is so important because once you start closing off big sections of your audience, you are losing money to be made from these audiences. The cultural argument is clear to see but what happens in the industry? You have to start engaging with the economics of diversity. We consciously need to be casting and thinking about different perspectives, and academic research can be very useful in thinking about how to mix revenue targets with cultural targets.

It is a difficult area to explore though. Think back to those early discussions about the "grey dollar." Television had ignored the older audience and yet the realization that they had money to spend gave advertisers and broadcasters an economic argument to chase them and finally represent them. The cultural argument had failed, but money spoke. I don't think it's 
quite as easy as this suggests, but what is clear is that we need more than just the cultural argument as that alone has failed to drive change. Many of the communities underrepresented in today's media are not economically powerful, so we need to discover their economic worth. Discrimination does cost, but what are the financial benefits of eradicating it? The evidence is mounting that geographical openness and cultural diversity and tolerance are not by-products but key drivers of economic progress. Proximity, openness, and diversity operate alongside technological innovation and human capital as the key engines of economic prosperity. Indeed, one might even go so far as to suggest that they provide the motive force of intellectual, technological, and artistic evolution. ${ }^{2}$

Julie Donovan: Since I started in the industry, diversity in the workplace has become a real problem. UK television production is predominately white and middle class, with many graduates who have parents willing and able to subsidize them working for free or on minimal wages while they gain valuable experience. It is a problem that the industry is trying to address. Equal access to internships would be a start; however, they often go to children of friends and never get offered outside of those with good connections.

Jeanette Steemers: There is a strong relationship between the producer and broadcaster where you retain rights, especially for public service media, but once you start doing business with subscription-based platforms, producers lose those rights. What can the industry do about this?

Jane Roscoe: Ownership of rights complicates business models. There is a mismatch between what is happening every day and how established broadcasters and producers are making a living, and it is an uncomfortable moment in business models right now. There needs to be one thing that shifts, perhaps around rights, because we are stuck, unable to reconceptualize the business models to keep up with how audiences are engaging today. At the moment, we have all these models that cause friction, all these agendas rubbing up against each other, and we need space to open up the conversations.

If we look at pirate audiences, perhaps that is the moment that disrupts the business models. To stop calling these people illegal and call them something else. Who will make the move to make this possible? Someone has to pay for quality content. There is a gap; how can we help the industry think of different business models? We are stuck, running around trying to find money for making programs. One way out of this is to think about audiences in different ways, how have other industries done it?

Annette Hill: $\quad$ To tap into illegal audiences, the industry will need to mix formal and informal economies, where there is a flow between the two. Studies in Australia, for example, highlight how pirate audiences are willing to pay for quality content, but they want such content immediately without geo-blocking or other kinds of restrictions, and they want content in flexible ways, without contracts that bind them for years on end. Flexible business models for flexible audiences this sort of approach can be a means of making space for business models that match new trajectories of engagement with a range of content. 
Douglas Wood: I am optimistic about television content production, but the way we think about our audiences and ultimately distribute this content to them is going through a period of change. At the end of the day, quality content comes at a high price and someone has to pay for this; the problem is that many of these fragmented audiences are yet to be commercialized and we have to think about how we monetize this growing and geographically diverse audience group. One of the benefits of the emergence of global subscription video on demand (SVOD) and over-the-top (OTT) services is that they have given many of these niche audiences a commercial value by providing a distribution mechanism that can reach them. However, there is a cultural risk that if global subscription services cherry-pick the best content, we may end up in a world of TV haves and have-nots, where only those who are willing to pay will get this quality programming. This is why public service broadcasting remains such an important part of the mix and has an obligation to seek out new ideas and take more risks in commissioning.

Julie Donovan: It is a challenging situation. However, a solution or more solutions do need to be found. Audiences are driving the need for new business models, and as this often illegal audience grows, the ability to monetize them will become a priority. Established distribution models are being challenged, but we can't pretend that everything can go backward or even stay the same.

Jane Roscoe: The broadcasters are responding differently to the challenges. For example, Walter Presents, which is a video-on-demand service with handpicked international drama, is one interesting move by Channel Four, or BBC 3 has moved online. Broadcasters are not going to give up; they are fighting for their lives, and they are willing to change and try things out. There is a period of trying out different models to see what works, spreading the economic risks.

\section{Jeanette Steemers: Will television still be relevant to audiences and their engagement with audio-visual content in five or ten years' time?}

Douglas Wood: I think we need to change our language when we talk about television. For me, the word television now includes all long-form video content watched across an increasingly diverse number of devices, from the traditional TV set in the corner of the room, to the mobile phone on the train. I think TV content is and will be relevant to audiences for the foreseeable future. If anything, it may actually grow in relevance as new viewing platforms and on-demand services are increasingly becoming content libraries that allow viewers to rediscover a vast catalogue of classic TV titles and series. And there is commercial value in these catalogues, Netflix and Hulu recently paid a lot of money to secure the rights to classic comedies such as Seinfeld and Friends, allowing a whole new generation of viewers the opportunity to discover these comedy classics.

One of the biggest problems we face is keeping up with these changing viewer patterns, how we measure it, and ultimately the commercial value we place on it. This recent research 
certainly helped our understanding of how diverse audiences can consume content in a more fluid way, and really showed how passionately our viewers engaged with the TV shows that they love. However, this research suggests that one of the biggest challenges is not for ourselves as content producers, but rather for broadcasters and platforms to find a way of delivering this content so that it matches these new patterns of viewer behavior.

Julie Donovan: I don't know why great storytelling would ever become irrelevant or go out of fashion. We do need to stay in tune with audiences and constantly look for ways in which to entertain and engage them. And there is also the perennial question of whether TV viewing becomes more prevalent with age. At forty, was I watching more TV than when I was in my twenties? Absolutely.

Annette Hill: We hear a lot of talk about television as legacy media. Far from being legacy, television is very relevant, it is just that we are watching it in myriad ways that are hard to capture. We spoke with fans of cult drama Utopia that called it a malleable art form, the freshest kind of storytelling for global audiences. This is television: it is just that we are struggling with what to call television that we choose to watch in our own way, on our own terms. It seems to me that television as multilayered storytelling will survive and flourish. Talk of mothballing is misdirection by political power players who have a stake in weakening broadcast and public service media.

Jane Roscoe: $\quad$ There is so much motivation to say television is in decline but what is the point of these discourses? There is some great content out there, and most of it originates from the broadcasters, but we are engaging with it in different ways that are hard to measure. It is all about changing the political and economic narratives to discuss engagement as quality, value, and relevance.

${ }^{1}$ Annette Hill is a Professor of Media and Communication at Lund University, Sweden. Her research focuses on audiences and popular culture, with interests in media engagement, everyday life, genres, production studies, and cultures of viewing. She is the author of seven books, and many articles and book chapters in journals and edited collections, which address varieties of engagement with reality television, news and documentary, television drama, entertainment formats, live events and sports entertainment, film violence, and media ethics. Her latest book is Reality TV (Routledge 2015), and her next book is Media Experiences (Routledge 2017).

Jeanette Steemers is Professor of Culture, Media and Creative Industries in the Department of Culture, Media and Creative Industries at King's College London. A graduate in German and Russian, she completed her PhD on public service broadcasting in West Germany in 1990. Her current research interests include the political economy of children's screen media, the future of public service broadcasting, and transformations in media distribution. Recent publications include Creating Preschool Television (2010), Global Media and National Policies (2016 coedited with T. Flew and P. Iosifidis) and European Media in Crisis (2016 coedited with J. Trappel and B. Thomass). 
Jane Roscoe is the Director and CEO of the London Film School. She was previously with SBS Television in Australia as Network Programmer, then Head of International Content. During her time in academia, her research focused on documentary, audiences, and factual television. She is coauthor of Faking It: Mock-Documentary and the Subversion of Factuality (MUP, 2001).

Julie Donovan is a formats consultant for the Media Experiences project (Wallenberg Foundation) with over twenty years of experience in the UK and international television production and formats business. Previously, she was Senior Vice President of International Format Development for Fremantlemedia, Format Consultant for Granada Media, and prior to that a producer on shows for LWT, ITV, BBC, Channel 4, and Channel 5. She is currently consulting on various projects, including one for the China Media Centre in London.

Douglas Wood has over twenty years of experience in television research and is currently Group Director of Research and Insight for Endemol Shine Group. He is an expert on global trends for the television industry and also oversees all research on the company's global hit formats such as Big Brother, The Island, and many more. He joined Shine Group in 2010 where he set up the global research and insight function, working on key formats such as MasterChef, The Bridge, and Broadchurch. Previous to his time at Endemol Shine, he spent twelve years at FremantleMedia as a research manager, working across international formats such as Idols, X Factor, and Got Talent. He began his career at UK broadcaster Channel 4.

${ }^{2}$ Quamrul Ashraf and Oded Galor, "Cultural Diversity, Geographical Isolation, and the Origin of the Wealth of Nations" (NBER Working Paper No. 17640, National Bureau of Economic Research, Cambridge, MA, December 2011). 